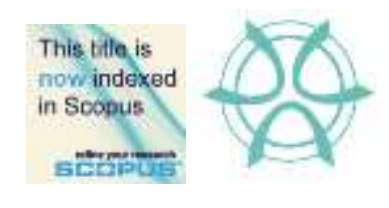

PLANNING MALAYSIA:

Journal of the Malaysian Institute of Planners

VOLUME 18 ISSUE 4 (2020), Page 128 - 143

\title{
ASSESSING CYCLE LANES USING THE BICYCLE COMPATIBILITY INDEX (BCI) IN SHAH ALAM, SELANGOR, MALAYSIA
}

\author{
Yusfida Ayu Abdullah ${ }^{1}$, Syifa'Azwa Ahmad Razi ${ }^{2}$, Na'asah Nasrudin ${ }^{3}$, \\ Zulkifli Ahmad Zaki ${ }^{4}$ \\ ${ }^{1,2,3,4}$ Faculty of Architecture, Planning and Surveying, \\ ${ }^{1,3,4}$ Responsive Environmental Development (RED) Research Group, \\ UNIVERSITI TEKNOLOGI MARA (UiTM)
}

\begin{abstract}
The evolution of bicycles is tremendous. Humans recognized its function, importance, and value this non-motorized vehicle as an important part of their daily life. In Malaysia, most urban roads are designed for the motor vehicle therefore cycling is not a greater option for commuting to workplaces. This study aims at assessing the compatibility level of cycle lanes. Section 14, Shah Alam, Malaysia was selected as the case study, and a questionnaire survey utilizing the Simple Random Sampling technique was conducted involving 133 samples. The Bicycle Compatibility Index (BCI) was applied to calculate the capability of bicycle lanes. Results demonstrated the weaknesses of bike path infrastructure and its compliance to guidelines. The compatibility level of cycle lanes is still low, therefore, suggesting an enhanced approach to the planning and development of cycle lanes. The outcome of this study can be a guide to the local authority yet applicable to other urban areas.
\end{abstract}

Keywords: Bicycle; Cycle Lanes; Bicycle Compatibility Index; Capability

${ }^{1}$ Assoc. Professor at Universiti Teknologi Mara (UiTM). Email: ayunazeri@gmail.com 
PLANNING MALAYSIA

Journal of the Malaysia Institute of Planners (2020)

\section{RESEARCH BACKGROUND}

Bicycles were first made popular in the 18th century with the creation of a larger wheel drive model and had evolved ever since to respond to consumers' demand. In 1885, an English man John Kemp Starley invented the first bicycle with safety measures. That invention is praised as one of the most significant moments of bicycle design because of the network that connects pedals to the rear wheels and the removable of front wheels. Thereafter, the Golden Age of Bicycles was shaped.

Bicycles are not only intended as a mode of transportation but also used for recreational and leisure purposes. Bikes are claimed as the number-one mode of transportation around the world. Sibilski (2015) estimates that there are over 2 billion bikes in use throughout the globe and predicts that the number would increase to five billion in 2050 . He thinks that more than 50 percent of the world population knows how to ride. The Netherlands holds the highest record of users with $99 \%$ of its population are cyclists (Kenny, 2015). In fact, in Amsterdam itself, there are over $500 \mathrm{~km}$ of bicycle lanes exist throughout the city (Gaada.com, 2015).

Private transportation is thought to be easier for individuals to move from one place to another. The demand for private vehicles has been increasing even though the capacity of roads is becoming alarming. To encourage more cyclists, bicycle facilities and the provision of dedicated lanes for cyclists have been introduced. This, in turn, would at least reduce traffic congestion in some urban areas which seems to be a great challenge in major cities in Malaysia. Cycling is deemed environmentally friendly because it does not produce emission and quiet too. Not only that but cycling also promotes good health and may reduce cardiovascular disease and other health issues (Theja Phutta, 2019). Cycling can help weight management, promotes good mental and physical health, and prevents or manages medical conditions (Cronkleton, 2020). However, currently, only $40 \%$ Malaysians adopted healthy lifestyle by making sports (such as cycling) as a culture (Ling et al., 2018). Furthermore, in Malaysia, cycling as a medium of transport to the workplace is said to receive little attention. A motor vehicle is more prevalent considering the weather and the distance from home to the workplace. Nevertheless, bicycles are gaining popularity for school children and teenagers to commute to school and are commonly known as a form of exercise among the public.

The main purpose of creating designated cycle lanes is to ensure a safe path for cyclists. Bike speed is usually much lower that of motor vehicles. Bicycles are light vehicles relative to other vehicles, which may result in injuries in the event of an accident.

Preliminary investigation for this study suggested that bicycle facilities are not effectively utilized and therefore demonstrating for lack of acceptance among the residents of Section 14, Shah Alam. Section 14, in Shah Alam which 
Yusfida Ayu Abdullah, Syifa'Azwa Ahmad Razi, Na'asah Nasrudin, Zulkifli Ahmad Zaki

Assessing Cycle Lanes Using the Bicycle Compatibility Index (BCI) in Shah Alam, Selangor, Malaysia

is situated in the State of Selangor, is densely developed with commercial buildings and activities. Part of Section 14 has a recreational area, but the provision of cycle lanes is not in total. The fact that the area is commercially focused, the area has increased road capacity which in turn affected bicycle lanes. An early investigation revealed that motorists tend to park their vehicles on cycle lanes which disrupt the efficiency of cyclists' movement (Figure 1). This invasion is inevitable as it requires constants inspection by the local authority enforcement unit.

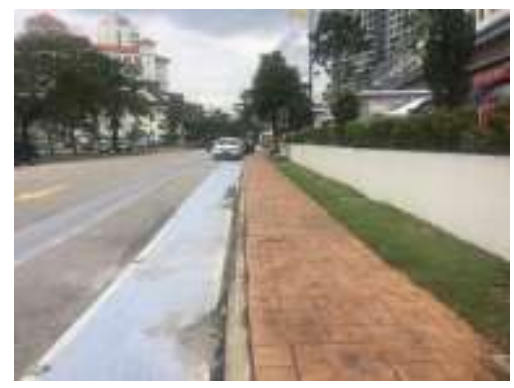

Figure 1: Invasion of Motorists on Cycle Lane Source: Author

Also, the route and placement of bicycle lanes can affect the use of bicycles in an area. The design and route of bicycle paths often consider the connectivity and link from one trail to another. However, some routes tend to be isolated and hidden from vicinity which to some extent influences the cyclist's sense of security and safety (Figure 2). Therefore, cycling is not the main option. The surroundings of bicycle lanes play an important role in affecting one's confidence in feeling or safety assurance. Location is also said to play a big role in walking and cycling decisions (Nasrudin et.al., 2014).
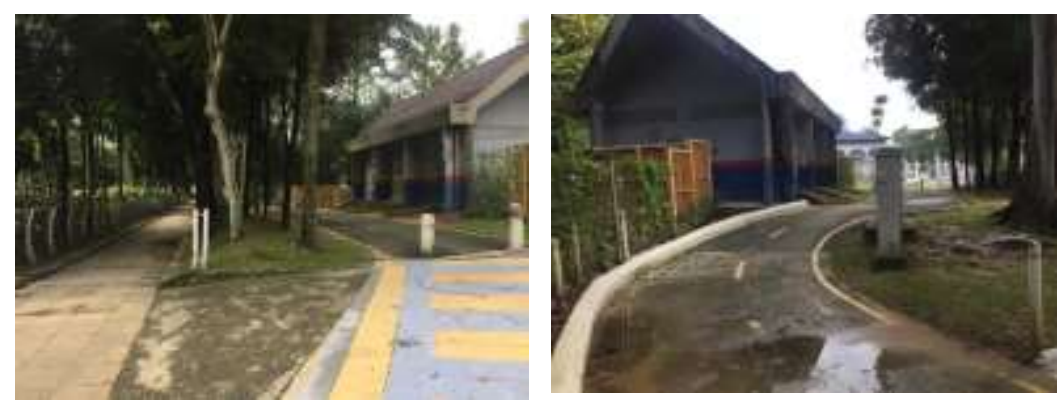

Figure 2: Cycle Lanes tend to be 'out of sight " Source: Author 
PLANNING MALAYSIA

Journal of the Malaysia Institute of Planners (2020)

The early investigation suggested that the local authority for Shah Alam, i.e. the Shah Alam City Council (known as MBSA) had focused its 2019 budget more on operating expenses rather than development (Yeen and Muthiah, 2019; Michael, 2018; The Sun Daily, 2018). The budget was focusing more on other development and little was mentioned about cycling paths even though the state government had launched its bicycle lanes (Low and Rajendra, 2019).

The Shah Alam City Council had aspired to encourage the reduction of carbon footprint in its city. The Shah Alam Local Plan 2020 targets the city as a low carbon city where it aims at reducing the capacity of private vehicles by encouraging the use of bicycles as a mode of transport (Selangor Town and Country Planning Department, 2014). The Low Carbon Action Plan was outlined for the year 2030 and targeted to achieve a reduction of $60 \%$ of $\mathrm{CO}_{2}$ emission by 2030 (Lin, 2017). Part of the self-evaluation results from the project was to incorporate pedestrian pavements and bicycle roads to elevate the efforts in achieving a low carbon city (Lin, 2017). Based on this study and Shah Alam's aspiration, it cannot be denied that provision and facilities for cyclists should gain more attention. Also, this ambition can be transpired through the support of the public, and therefore, more initiatives should be executed to convey the government's intention. In 2017, a study in Shah Alam revealed that there was a reduction of 12,173 vehicles based on the 2015 baseline (Green Tech Malaysia, 2019). This positive achievement inevitably becomes a challenge to the local authority to accomplish more and be a reference to other local authorities in Malaysia which had adopted the Low Carbon City Framework (LCCF).

This study, therefore, aimed at assessing cycling lanes in an urban area in Malaysia, by employing the measuring tool named as the Bicycle Compatibility Index (BCI). The intention was to evaluate the capability of bicycle lanes (LOS) and the users' perception with regards to the provision and facilities for cyclists. The outcome of this study was expected to increase the level of accessibility for cyclists and accommodate the local authority's future planning, as well as be guidance to other stakeholders involved in the design and provision of cycle lanes or cycle paths.

\section{LITERATURE REVIEW}

\section{Bicycle Lanes}

Bicycles lanes or cycle paths are pathways or special paved lanes, or spaces dedicated for cyclists only. Cycle lanes can either be shared with pedestrians known as urban bike networks (Figure 3 (a)) or designed for cyclist usage only. However, shared lanes require a bigger space (Figure 3 (b)). There are also bicycle lanes adjoining the road for motor vehicles but are separated through designated markings like colour or markings. This type of cycle lanes joins with the road within the boundaries of the roads' laneway. Therefore, the roads are normally with wider shoulders (Figure 3 (c)). Otherwise, cycle lanes are 
Yusfida Ayu Abdullah, Syifa'Azwa Ahmad Razi, Na'asah Nasrudin, Zulkifli Ahmad Zaki

Assessing Cycle Lanes Using the Bicycle Compatibility Index (BCI) in Shah Alam, Selangor, Malaysia

controlled lanes where bollards, fences, or soft landscapes become the barrier or partition to detach between the road and the cycle lanes Figure $3(\mathrm{~d})$ ) (Jsoulliere, 2017).

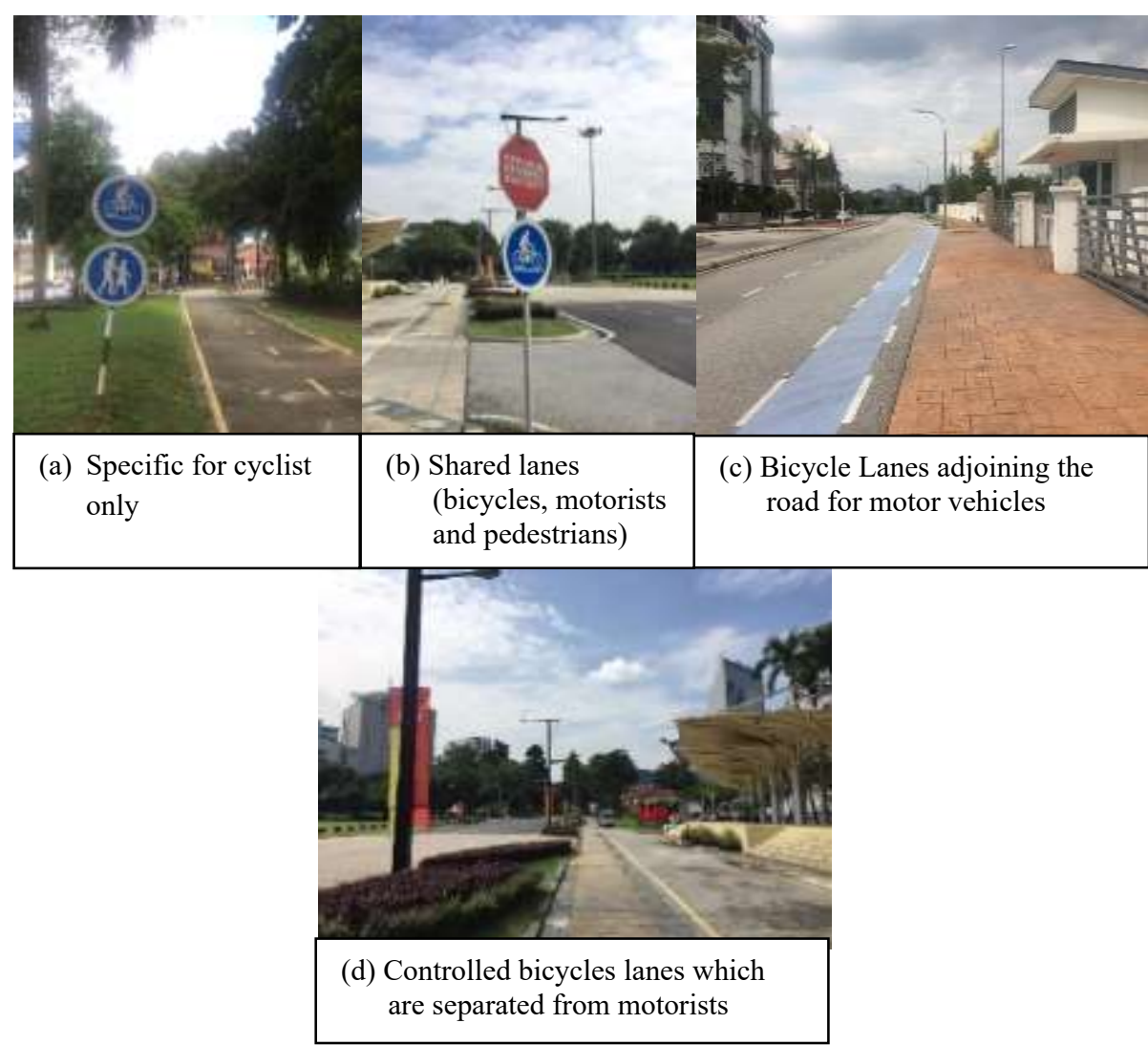

Figure 3: The types of cycle lanes Source: Author

\section{Planning and Guidelines of Bicycle Lanes in Malaysia}

In Malaysia, guidance on the design of laneways which incorporates bicycle lanes was first addressed in 2012 in the Green Neighbourhood Guideline (PLANMalaysia, 2012). However, the principles of design were brief. But in 2013, PLANMalaysia (formerly known as the Department of Town and Country Planning Peninsular Malaysia) had produced its explicit manual for bicycle lane which is devoted to bicycle planning, design, and development (PLANMalaysia, 2013). The manual is comprehensive and furnished with principles of planning and supported by illustrations in terms of design aspects (Figure 4). The standards for bicycle lane provision are divided into three (3) categories, namely; for non- 
residential, residential, and for the public-focused area. For non-residential areas, components of design must encourage pedestrian access by emphasizing sidewalks, pedestrian lanes, and transit stops. Part of the design elements for the green neighbourhood was addressed as "routes through parks, open spaces and connect to the local street network while storage in secure and protected areas" (PLANMalaysia, 2017). The rule-of-thumb was to ensure that the cycle lane network should be interconnected with residential areas, neighbourhoods, commercial areas, and transit facilities for accessibility of all groups of the public (PLANMalaysia, 2013).

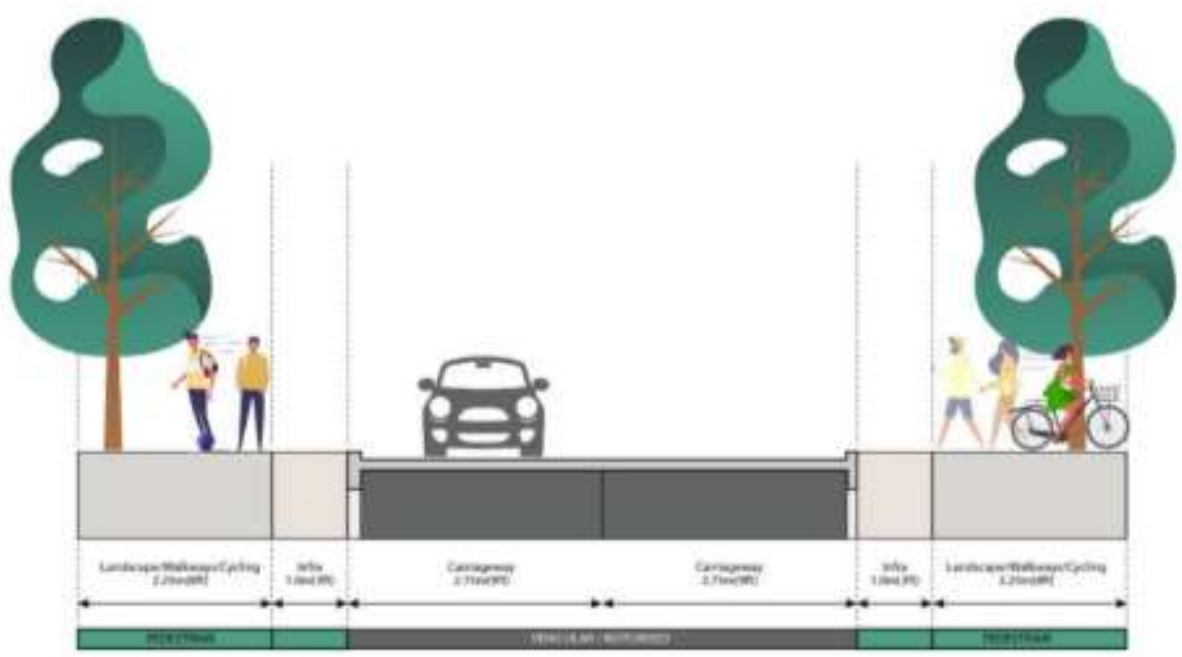

Figure 4: A cross-section of a 12-metre width road provision with an allocation of 1.53 metres of cycle lane for each side or 2.25 meters including the street furniture Source: Redrawn from PLANMalaysia, 2013

\section{Bicycle Compatibility Index (BCI)}

The Bicycle Compatibility Index (BCI) evaluates the capability of urban and suburban roadway sections to accommodate both motorists and cyclists (Harkey et.al, 1998). It is also applied to examine cycle lane facilities in urban areas to determine the geometric and operational requirements for improvement (Eren et.al, 2019).

The approach to the BCI model is by capturing users' perceptions and evaluate the comfort level of a cyclist (Illie et.al, 2016). To attract more cyclists, the element of comfort and safety are essential (Kwigizile, Oh and Lyimo, 2019). However, the BCI is adapted for mid-road segment use only, or roads with traffic. Therefore, any major intersection of the roadway facing traffic stops or traffic congestion will not be considered as part of the Level of Service (LOS) 
Yusfida Ayu Abdullah, Syifa'Azwa Ahmad Razi, Na'asah Nasrudin, Zulkifli Ahmad Zaki

Assessing Cycle Lanes Using the Bicycle Compatibility Index (BCI) in Shah Alam, Selangor, Malaysia

assessment. According to BCI, LOS is examined from the user's perceptions of qualitative measures based on the operational conditions of the road.

\section{METHODOLOGY}

The study uses Section 14, the city centre of Shah Alam, situated in the State of Selangor, in Malaysia as a case study (Figure 5). Shah Alam City Council is known for its efforts in developing cycle lanes which spent almost RM5million on bicycle infrastructure around its city including Section 14. The bicycle infrastructure was launched in July 2013. Section 14 is highly developed with commercial and administrative buildings. A simple random sampling method was applied to gain user's perception to assess the LOS from the application of the BCI. 133 samples or cyclists were picked randomly at the site to represent the population size of 157,210 .

The survey was conducted during weekdays and weekends (7 days in a week) to reach a total of $133(100 \%)$ respondents based on sampling calculation. Each day, the survey was performed in the morning $(7.00 \mathrm{am}-10.00 \mathrm{pm})$ and in the evening $(4.00 \mathrm{pm}-7.00 \mathrm{pm})$ targeting the peak hours and the common hours for traveling and recreational purposes. The survey was not carried out in the afternoon based on the result from the early investigation. Since Malaysia experiences hot temperatures in the afternoon, therefore, it is not a usual practice to cycle in the hot weather.

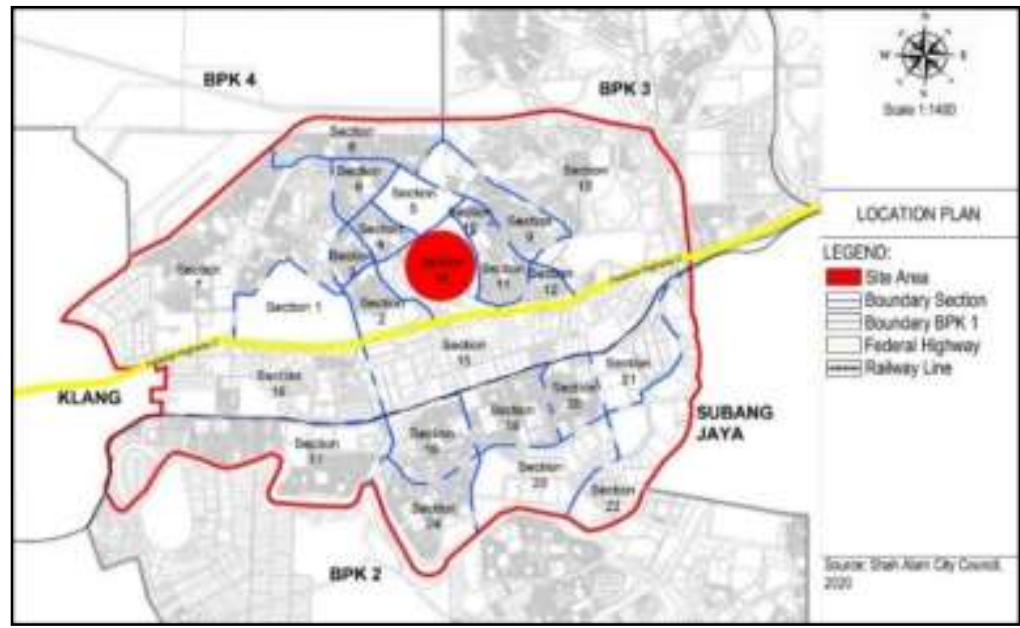

Figure 5: Location Plan of the Study Area Source: Shah Alam City Council, 2020 
12 segments of cycle lanes were selected in Section 14 and each segment was evaluated using the BCI Index using the equation and Table 1 below (Harkey et.al, 1998):

Equation: $\mathrm{BCI}=3.67-0.966 \mathrm{BL}-0.410 \mathrm{BLW}-0.498 \mathrm{CLW}+0.002 \mathrm{CLV}$

$+0.00040 L V+0.022 S P D+0.506$ PKG - 0.264 AREA + AF

Table 1: Variable Definitions for Bicycle Compatibility Index (BCI)

\begin{tabular}{|c|c|c|c|}
\hline $\mathrm{BL}=$ & $\begin{array}{l}\text { presence of a bicycle lane or } \\
\text { paved } \\
\text { shoulder } \geq 0.9 \mathrm{~m} \\
\text { no }=0 \\
\text { yes }=1\end{array}$ & PKG= & $\begin{array}{l}\text { presence of a parking lane with more } \\
\text { than } 30 \text { percent occupancy } \\
\text { no }=0 \\
\text { yes }=1\end{array}$ \\
\hline BLW= & $\begin{array}{l}\text { bicycle lane for paved laneway } \\
\text { curb } \\
\mathrm{m} \text { (to the nearest tenth) }\end{array}$ & AREA= & $\begin{aligned} & \text { type of roadside development } \\
& \text { residential }=1 \\
& \text { other type }=0\end{aligned}$ \\
\hline$C L W=$ & $\begin{array}{l}\text { curb lane width } \\
\mathrm{m} \text { (to the nearest tenth) }\end{array}$ & $\mathbf{A F}=$ & $\begin{array}{l}f_{t}+f_{p}+f_{n} \\
\text { Where: }\end{array}$ \\
\hline CLV $=$ & $\begin{array}{l}\text { curb lane volume } \\
\text { vph in one direction }\end{array}$ & & $\begin{array}{l}\mathrm{f}_{\mathrm{t}} \quad \text { Adjustment factor for truck } \\
\text { volumes (see below) }\end{array}$ \\
\hline OLV $=$ & $\begin{array}{l}\text { other lane(s) volume - same } \\
\text { direction } \\
\text { vph }\end{array}$ & & $\begin{array}{l}\mathrm{f}_{\mathrm{p}} \quad \text { Adjustment factor for parking } \\
\text { turnover (see below) }\end{array}$ \\
\hline SPD $=$ & $\begin{array}{l}85^{\text {th }} \text { percentile speed of traffic } \\
\mathrm{km} / \mathrm{h}\end{array}$ & & $\begin{array}{l}\mathrm{f}_{\mathrm{n}} \quad \text { Adjustment factor for right-turn } \\
\text { volumes (see below) }\end{array}$ \\
\hline
\end{tabular}

\begin{tabular}{|c|c|c|c|}
\hline \multicolumn{4}{|c|}{ Adjustment Factors } \\
\hline $\begin{array}{l}\text { Hourly Curb } \\
\text { Lane Large } \\
\text { Truck Volume }\end{array}$ & $f_{t}$ & $\begin{array}{l}\text { Parking } \\
\text { Time } \\
\text { Limit } \\
\text { (min) }\end{array}$ & $f_{p}$ \\
\hline $\begin{array}{c}\geq 120 \\
60-119 \\
30-59 \\
20-29 \\
10-19 \\
<10\end{array}$ & $\begin{array}{l}0.5 \\
0.4 \\
0.3 \\
0.2 \\
0.1 \\
0.0\end{array}$ & $\begin{array}{c}\leq 15 \\
16-30 \\
31-60 \\
61-120 \\
121- \\
240 \\
241- \\
480 \\
>480\end{array}$ & $\begin{array}{l}0.6 \\
0.5 \\
0.4 \\
0.3 \\
0.2 \\
0.1 \\
0.0\end{array}$ \\
\hline $\begin{array}{l}\text { Hourly truck } \\
\text { turn volume }\end{array}$ & $f_{n}$ & & \\
\hline $\begin{array}{l}\geq 270 \\
<270\end{array}$ & $\begin{array}{l}0.1 \\
0.0\end{array}$ & & \\
\hline
\end{tabular}

Figure 6 below shows the cycling lanes of the study area. The selected bikeways were mostly the lanes accompanied by commercial buildings. 
Yusfida Ayu Abdullah, Syifa'Azwa Ahmad Razi, Na'asah Nasrudin, Zulkifli Ahmad Zaki

Assessing Cycle Lanes Using the Bicycle Compatibility Index (BCI) in Shah Alam, Selangor, Malaysia

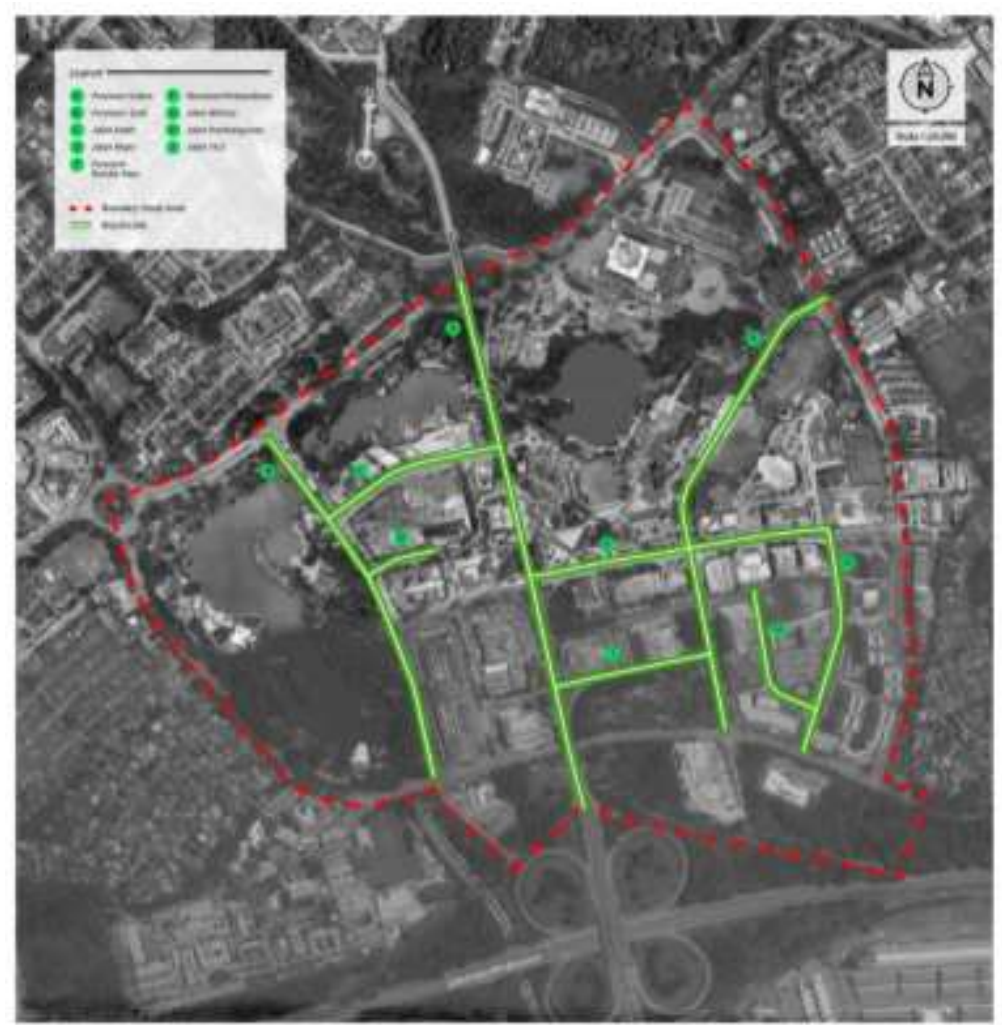

Figure 6: Bike Paths marked in 'green lines' in the Study Area Source: Google Maps, 2020

Meanwhile, the Level of Service (LOS) was applied to evaluate the operational aspect, which identifies the most appropriate routes and determine the poor links. Also, LOS examines the design of roadways to assess the compatibility of bicycle usage (Liu, Homma and Iki, 2019). Otherwise, it can examine the planning aspect which can be a reference for future planning and improvement. Table 2 below shows the designations of LOS and compatibility level qualifiers.

Table 2: BCI Associated with LOS Designations and Compatibility Level Qualifiers

\begin{tabular}{ccc}
\hline LOS & BCI Range & Compatibility Level \\
\hline A & $<1.50$ & Extremely High \\
\hline B & $1.51-2.30$ & Very High \\
\hline C & $2.31-3.40$ & Moderately High \\
\hline D & $3.41-4.40$ & Moderately Low \\
\hline E & $4.41-5.30$ & Very Low \\
\hline F & $>5.30$ & Extremely Low \\
\hline & Source: Research Development and Technology (1999)
\end{tabular}


PLANNING MALAYSIA

Journal of the Malaysia Institute of Planners (2020)

\section{RESULTS AND DISCUSSION \\ Results from Users' Perceptions}

Based on the survey, the study revealed that from 133 respondents, $34.2 \%$ cycle in the morning. This figure does make sense because most of the cyclists $(40.5 \%)$ work in the private sector and office hour for private sector normally starts at 9.00 am. However, only $3.8 \%$ of the total respondents ride every day as a form of exercise and this figure represents most male cyclists. However, the majority (34.2\%) only ride once a month. The researchers felt that this frequency is a challenge for the local authority in envisaging the city as a low carbon city. The study showed that only $15.2 \%$ cycle at least 5 times a week.

Most cyclists (82\%) ride for recreational purposes. Only 5\% think that cycling avoids traffic congestion, while $2 \%$ understood the importance of protecting the environment from fuel combustion. This situation shows that the public has yet to become aware of the preservation of the environment. Bike paths or cycle lanes are part of environmental protection efforts; therefore, the Shah Alam City Council needs to diversify its initiatives with the community to raise awareness of the vulnerabilities and effects of too many private vehicles on the road. However, it cannot be denied that the weather and distance of one's home and workplace do play a significant role in whether to cycle or to drive. Several obstacles were highlighted by the respondents which hinder them from cycling. A high percentage of cyclists (46\%) claimed that the weather condition influences their choice for mode of transport. The hot afternoon weather and the frequent rain made them uncomfortable to cycle. Furthermore, the cycle lanes in Section 14 are not covered and a cyclist is not protected against hot weather and heavy rain. The other obvious reason was the safety aspect. Cyclists (39\%), felt that without any barriers or partitions from the road, they feel unsafe while cycling because motorists often do not compromise with the $50 \mathrm{~km} / \mathrm{h}$ speed limit which creates an unsafe cycling experience.

\section{Motorists' Behaviour Vs. Cyclists' Right}

Site observations were carried out several times which includes two observations for the pilot observation study, i.e. once on a weekday and once on a weekend; and twice for the actual observation study, also on a weekday and a weekend. During the pilot study, site observations were performed in the morning, afternoon, and evening. But the actual observation study only took place in the morning $(7.00 \mathrm{am}-10.00 \mathrm{am})$ and evening $(4.00 \mathrm{pm}-7.00 \mathrm{pm})$. Results revealed that some motorists were not observing the cycle lane. Several vehicles were seen parked on cycle lanes. This behaviour inescapably blocks the cycle lanes and cyclists will need to cycle on the road (for motorists) to escape the vehicle. Part of the motorists' actions may be caused by escaping to park further from the 
Yusfida Ayu Abdullah, Syifa'Azwa Ahmad Razi, Na'asah Nasrudin, Zulkifli Ahmad Zaki

Assessing Cycle Lanes Using the Bicycle Compatibility Index (BCI) in Shah Alam, Selangor, Malaysia

building or avoiding the drop-off bay, or inadequate parking space. Unfortunately, cyclists must deal with such an attitude, but this action is likely to happen even on weekend (Figure 7).
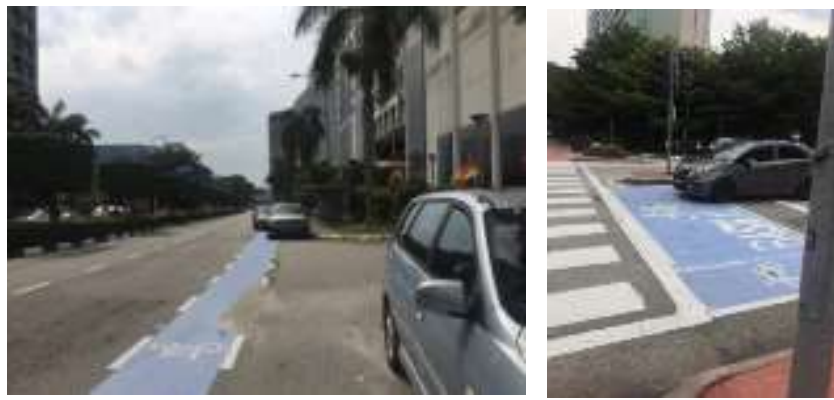

Figure 7: Motorists are Denying the Right of Cyclists Source: Author

\section{The Reality}

The study discovered that the main issue of cycle lanes in Section 14 Shah Alam was the width of cycle lanes. Most of the cycle routes are below the ideal standard directed by PLAN Malaysia (2013) which requires a dedicated cycle lane of 1.53 meters in width (not for shared lane). In Section 14, most lanes are only 1.1meter (see example in Figure 8).

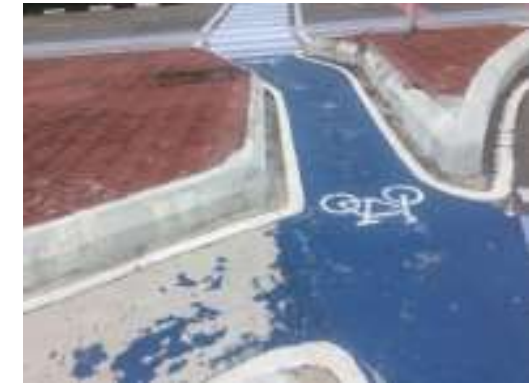

Figure 8: Cycle lane is narrow Source: Author

The volume of motor vehicles during peak hours is high causing the cyclists to be uncomfortable and unsafe. Moreover, at most of the roadways, the speed limit for motor vehicles is $50 \mathrm{~km} / \mathrm{h}$. This condition also affects the sense of comfort for the users. Respondents complained that motorists tend to drive on cycle lanes because there are no barriers to segregate between the cycle lanes and the road, making it unsafe for the cyclists. Also, the fact that most cyclists only ride for recreational purposes and mostly cycle once a month makes it difficult to achieve the city council's endeavour to achieve as a low carbon city and persuades its residents to commute by bicycle. What's more, only $2 \%$ believe that cycling will reduce transportation costs and just a $1 \%$ cycle because it is the only option the person has. 
PLANNING MALAYSIA

Journal of the Malaysia Institute of Planners (2020)

\section{Results from Bicycle Compatibility Index (BCI) and LOS Assessment}

Using the equation of the Bicycle Compatibility Index (BCI), 12 segments of cycle lanes in Section 14 were calculated to derive its LOS. The elements of the $\mathrm{BCI}$ had contributed to determining the level of comfort of cyclists in the study area. The analysis revealed that the design, surrounding land uses, traffic operation, as well as parking area have a significant impact on determining the index value. Basically, out of 12 segments of cycle lanes, a segment positioned at Persiaran Sultan was calculated as 'extremely low' in terms of its LOS. 6 segments of cycle lanes received the BCI level as 'very low' LOS, which means that these lanes are not comfortable for cyclists. Otherwise, the LOS for the other 4 segments of cycle lanes was determined as 'moderately high' and the remaining segment resulted in 'moderately low' (Table 3) (Figure 9).

Table 3: LOS for 12 Segments of Cycle Lanes in Section 14, Shah Alam

\begin{tabular}{lccl}
\multicolumn{1}{c}{ Road } & BCI & $\begin{array}{c}\text { Level of Service } \\
\text { (LOS) }\end{array}$ & $\begin{array}{c}\text { Bicycle } \\
\text { Compatibility Level }\end{array}$ \\
\hline Persiaran Tasik & 4.54 & $\mathrm{E}$ & Very Low \\
Jalan Indah & 2.66 & $\mathrm{C}$ & Moderately High \\
Jalan Majlis & 2.96 & $\mathrm{C}$ & Moderately High \\
Persiaran Sultan & 10.25 & $\mathrm{~F}$ & Extremely Low \\
Persiaran Perbandaran (a) & 4.66 & $\mathrm{E}$ & Very Low \\
Persiaran Perbandaran (b) & 4.48 & $\mathrm{E}$ & Very Low \\
Jalan 14/2 & 2.80 & $\mathrm{E}$ & Very Low \\
Persiaran Bandaraya (a) & 4.82 & $\mathrm{E}$ & Very Low \\
Persiaran Bandaraya (b) & 4.67 & $\mathrm{E}$ & Very Low \\
Persiaran Bandaraya (c) & 4.03 & $\mathrm{D}$ & Moderately Low \\
Jalan Ikhtisas & 3.23 & $\mathrm{C}$ & Moderately High \\
Jalan Pembangunan & 2.67 & $\mathrm{C}$ & Moderately High \\
\hline \multicolumn{2}{c}{} & & Source: Author
\end{tabular}

The results from the BCI calculation was paralleled with the respondents' views. The majority argued that the design of the cycle lanes is narrow, and cyclists are not comfortable with the width. Similarly, the researchers felt that the width of cycle lanes is not in compliance with the ideal width suggested in the manual by PLANMalaysia (2013). Other than that, the majority $(46.6 \%)$ felt the distraction from other vehicles which cause them to be uncomfortable on cycle lanes. 
Yusfida Ayu Abdullah, Syifa'Azwa Ahmad Razi, Na'asah Nasrudin, Zulkifli Ahmad Zaki

Assessing Cycle Lanes Using the Bicycle Compatibility Index (BCI) in Shah Alam, Selangor, Malaysia

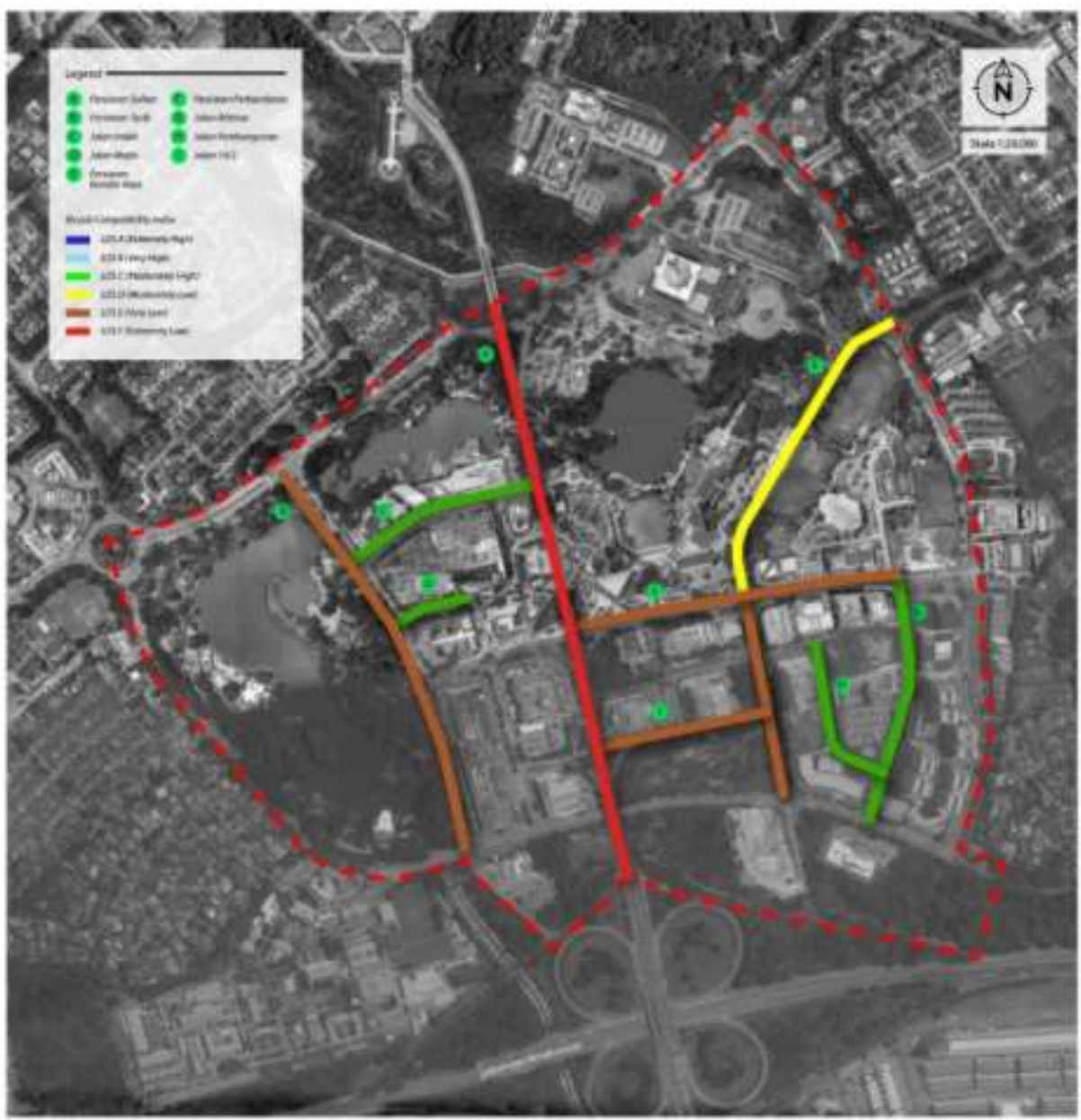

Figure 9: LOS of Bicycle Compatibility Index Source: Google Maps, 2020

Based on the results from the study, it is apparent that overall, the LOS of cycle lanes in Section 14 is not fully regarded as good and requires a continuous follow-up study to evaluate its performance and the extent of attractions for the benefits of cycling preference and to encourage cyclists to ride more than driving motor vehicles.

\section{CONCLUSION}

The study had examined the level of service of bicycle lanes, through the application of the Bicycle Compatibility Index (BCI). The results demonstrated mostly low LOS for cycle lanes in Section 14 Shah Alam. Cyclists expressed their concern about the width of cycle lanes alongside the road due to the speed limit 
for motor vehicles. Many cyclists are still commuting by motor vehicles and bicycles are used for recreational purposes. Only a few cyclists ride daily while most cyclists ride once a month in Section 14. Cycling is still far from becoming a preference to commute to the workplace due to hot weather and frequent rain. Motorists also contributed to the unsafe feeling from the illegal parking on cycle lanes. The Shah Alam City Council needs to monitor and record these behaviours continuously which in turn can provide ideas for future improvement or new cycle lanes. This study had shown that a bicycle is still not an option or approach to adopt to achieve a low carbon city status. Perhaps the city council would conduct a detailed study on this matter. Other future research may include the need for additional cycle routes and lanes in Section 14 or anywhere in Shah Alam which has linkages from one section to another. The researchers believe that the outcome of this study can be a reference to the local authority.

\section{REFERENCES}

Eren, E., Avsar, E., Yildirim, Z.B. and UZ, V.E. (2019) Investigation of Urban Bicycle Roads in Terms of Bicycle Compatibility, 2nd International Congress on Engineering and Architecture, 22-24 April 2019, Marmaris, Turkey. Available at: https://www.researchgate.net/profile/Ezgi_Eren3/publication/332672359_Investi gation_of_Urban_Bicycle_Roads_in_terms_of_Bicycle_Compatibility/links/5ce 5065d92851c4eabb5004f/Investigation-of-Urban-Bicycle-Roads-in-terms-ofBicycle-Compatibility.pdf

Cronkleton, E. (2020) 11 Benefits of Cycling Plus Safety Tips. Available at: https://www.healthline.com/health/fitness-exercise/cycling-benefits

Gaada.com (2015) List of Top Countries with Most Bicycles per Capita. Available at: http://www.gaadi.com/cycles/news/list-of-top-countries-with-most-bicycles-percapita

Google Maps (2020) Shah Alam, Seksyen 14. Available at: https://www.google.com.my/maps/place/Seksyen+14,+40000+Shah+Alam,+Sela ngor/@3.0748984,101.5144937,1632m/data=!3m1!1e3!4m5!3m4!1s0x31cc527d f9cf651b:0x468172009d72f033!8m2!3d3.074945!4d101.5184498

Green Tech Malaysia (2019) Building A Low-Carbon Metropolis. Available at: https://www.greentechmalaysia.my/building-a-low-carbon-metropolis/

Harkey, D.L., Reinfurt, D.W., Knuiman, M., Stewart, J.R. and Sorton, A. (1998) The Bicycle Compatibility Index: A Level of Service Concept, Implementation Model, Office of Safety and Traffic Operations, Research and Development. Available at: https://nacto.org/wp-content/uploads/2015/04/bci.pdf

Illie, A., Oprea, C. Costecsu, D. Rosca, E., Dinu, O. and Ghinea, F. (2016) The Use of the Bicycle Compatibility Index in Identifying Gaps and Deficiencies in Bicycle Networks, IOP Conf. Series: Materials Science and Engineering, 161 (2016) 012097, 20th Innovative Manufacturing Engineering and Energy Conference 
Yusfida Ayu Abdullah, Syifa'Azwa Ahmad Razi, Na'asah Nasrudin, Zulkifli Ahmad Zaki

Assessing Cycle Lanes Using the Bicycle Compatibility Index (BCI) in Shah Alam, Selangor, Malaysia

(IManEE 2016). DOI:10.1088/1757-899X/161/1/012097

Jsoulliere (2017) Lanes and Sharrows and Buffers..Oh My. Four Types of Bike Lanes Explained. Available at: https://www.smartcitiesdive.com/ex/sustainablecitiescollective/lanes-andsharrows-and-buffers-oh-my-four-types-bike-lanes-explained/1200740/

Kenny, S. (2015) Which Country Cycles More Than Any Other in the World. Here's the Top 10. Available at: https://mpora.com/road-cycling/which-country-cyclesmore-than-any-other-in-the-world-heres-the-top-10/

Kwigizile, V., Oh, J. and Lyimo, S.M. (2019) 18-02 Investigating and Prioritizing Factors for Quantifying Bikeability, Transportation Research Centre Reports, 45. Available

https://scholarworks.wmich.edu/cgi/viewcontent.cgi?article=1044\&context=tran sportation-reports

Ling, O.H.L., Nur Hidayah, S., Marlyana Azyyati, M. \& Sharifah Zannierah, S.M. (2018). Healthy lifestyle of public residents. Case study: Sri Pahang public housing, Bangsar, Kuala Lumpur Malaysia. Planning Malaysia Journal, 16 (3), 1-12.

Lin, H.W. (2017) Review on the LCT Planning of Shah Alam City, Selangor. Available at:https://aperc.or.jp/file/2017/9/20/15101530_Review_Expert_Presentation_Sha h+Alam_Lin0913.pdf

Liu, Q., Homma, R. and Iki, K. (2019) Utilizing Bicycle Compatibility Index and Bicycle Level of Service for Cycleway Networks, MATEC Web of Conferences, 259, 03005 (2019). DOI: 10.1051/matecconf/201925903005

Low, C. and Rajendra, E. (2019) New Lanes A Good Idea, Say Cyclists. Available at: https://www.thestar.com.my/metro/metro-news/2019/05/01/new-lanes-a-goodidea-say-cyclists

Michael, K. (2018) MBSA Unveils Smaller RM458mil Budget for 2019, with RM119mil for development. Available at: https://www.thestar.com.my/metro/metronews/2018/10/02/mbsa-unveils-smaller-rm458mil-budget-for-2019-withrm119mil-for-development

Nasrudin, N. A., Rostam, K., \& Noor, H. M. (2014). Barriers and Motivations for Sustainable Travel Behaviour: Shah Alam residents' Perspectives. Procedia Social and Behavioral Sciences, 153, 510-519. doi: 10.1016/j.sbspro.2014.10.084

PLANMalaysia (2012) Garis Panduan Perancangan Kejiranan Hijau. Available at: http://www.planmalaysia.gov.my/index.php/en/garis-panduanperancangan/2083-5-gp024-gpp-kejiranan-hijau/file

PLANMalaysia (2013) Panduan Pelaksanaan Inisiatif Pembangunan Kejiranan Hijau. Penyediaan Laluan Basikal. Available at: https://rehdaselangor.com/wpcontent/uploads/3c.-Penyedian-Laluan-Basikal.pdf

PLANMalaysia (2017) Green Neighbourhood in Malaysia. Available at: http://www.planmalaysia.gov.my/index.php/en/agensi/penerbitan- 
planmalaysia/artikel/1937-green-neighbourhood-in-malaysia/file

Research Development and Technology (1999) The Bicycle Compatibility Index (2016) Available

file://C:/Users/User/Desktop/TRP\%20Seminar\%20(PMJ\%202020)/Bicycle\%20

Compatibility\%20Index\%20(BCI)/2019\%20techbrief0799.pdf

Selangor Town and Country Planning Department (2014) Rancangan Tempatan Shah Alam 2020. Selangor: Jabatan Perancangan Bandar dan Desa Negeri Selangor.

Sibilski, L.J. (2015) Why We Need to Encourage Cycling Everywhere. Available at: https://www.weforum.org/agenda/2015/02/why-we-need-to-encourage-cyclingeverywhere/

Theja Putta, V.V.K. (2019) Evaluating Bicycle Networks: Visualizing and Measuring Low-Stress Connectivity and Accessibility, PhD Dissertation, Northeastern University, Boston, Massachusetts.

The Sun Daily (2018) Selangor State Government Tables RM2.56b Budget for 2019. Available at: https://www.thesundaily.my/local/selangor-state-govt-tables-rm256b-budget-for-2019-CA156136

Yeen, O.I and Muthiah, W. (2019) RM2.33 Billion Budget for S'gor. Available at: https://www.thestar.com.my/news/nation/2019/11/02/rm233bil-budget-for-sgor

Received: $15^{\text {th }}$ May 2020. Accepted: $1^{\text {st }}$ Sept 2020 